Pacific Journal of Mathematic 


\title{
A FIXED POINT THEOREM FOR PRODUCT SPACES
}

\author{
ALI A. ForA
}

We prove the following result in this paper: Let $(X, d)$ be a complete metric space and $Y$ be a space having the fixed point property. Let $f: X \times Y \rightarrow X \times Y$ be a continuous map. If $f$ is a contraction mapping in the first variable, then $f$ has a fixed point.

This result is a generalization to the result obtained in Nadler [5].

Other results are proved concerning the fixed point theorem for product spaces.

The concept "continuous height-selection" is discussed and its relation to the existence of fixed points for a function is also discussed.

1. Introduction. Given a function $f: X \rightarrow X$, fixed point theory is concerned with the questions of the existence, nature and number of points $x \in X$ such that $f(x)=x$.

The problem of whether the fixed-point property (f.p.p. for short) is, or is not necessarily invariant under cartesian products is an old one (see [2] and [3] for its history). As is well-known, examples due to Connell in the category of metric spaces, to Lopez in the category of polyhedra, and to Bredon in the category of polyhedra with the Shih condition show that the answer is negative in these categories, ([2] and [3]). In a certain sense the reason for the failure in the latter examples of the invariance of the f.p.p. under products is due to special local properties of the space under consideration. The first indication that the invariance could fail for homotopy-theoretic reasons came to light when Bredon discovered cell complexes $X_{\alpha}$ of the form $S^{k} U_{\alpha} D^{2 m}$ with the f.p.p. whose product $X_{\alpha} \times X_{\beta}$ fails to have the f.p.p. ([1]). A nice article by Husseini [4] shows that there are also manifolds with the f.p.p. whose product fails to have f.p.p.

Although the f.p.p. is not preserved under cartesian products in general, it is preserved when the maps $f: X \times Y \rightarrow X \times Y$ have special contraction properties. We prove the following theorem.

THEOREM 1.1. Let $(X, d)$ be a complete metric space, let $Y$ be a topological space with the f.p.p. and let $f$ be a continuous function from $X \times Y$ into $X \times Y$. If $f$ is a locally contraction mapping in the first variable, then $f$ has a fixed point.

(For the definition of locally contraction mapping see $\S 2$. ) 
The above theorem is a generalization of the following two theorems obtained by Nadler (see [5]).

THEOREM 1.2 (Nadler). Let $\left(X, d_{X}\right)$ be a complete metric space, let $\left(Y, d_{Y}\right)$ be a metric space with the f.p.p., and let $f$ be a function from $X \times Y$ into $X \times Y$. If $f$ is uniformly continuous on $X \times Y$ and a contraction mapping in the first variable, then $f$ has a fixed point.

THEOREM 1.3 (Nadler). Let $\left(X, d_{X}\right)$ be a complete metric space, let $\left(Y, d_{Y}\right)$ be a metric space with the f.p.p., and let $f$ be a function from $X \times Y$ into $X \times Y$. If $\left(X, d_{X}\right)$ is locally compact and $f$ is continuous on $X \times Y$ and a contraction mapping in the first variable, then $f$ has a fixed point.

In Theorem 1.1 we don't need $f$ to be uniformly continuous on $X \times Y$; neither we need the metrizability of $Y$ nor the locally compactness of $X$. For these reasons, Theorem 1.1 is a generalization of each of Theorem 1.2 and Theorem 1.3.

In what follows $p r_{1}: X \times Y \rightarrow X$ will denote the first projection mapping defined by $p r_{1}(x, y)=x$, while $p r_{2}: X \times Y \rightarrow Y$ will denote the second projection mapping defined by $p r_{2}(x, y)=y$.

2. Fixed point theorem and product spaces. Let us start this section with the following definition.

DEFINITION 2.1. Let $(X, d)$ be a metric space and $Y$ be any space. Let $f$ be a mapping from $X \times Y$ into $X \times Y$. Then $f$ is said to be a locally contraction mapping in the first variable if and only if for any $y \in Y$ there exist an open set $V(y)$ containing $y$ and a real number $\lambda(y) \in[0,1)$ such that

$d\left(p r_{1} f(x, v), p r_{1} f\left(x_{*}, v\right)\right) \leqq \lambda(y) d\left(x, x_{*}\right)$ for all $x, x_{*} \in X$ and all $v \in V(y)$.

A mapping $f: X \times Y \rightarrow X \times Y$ is called a contraction mapping in the first variable if and only if there exists a real number $\lambda \in$ $[0,1)$ such that for any $y \in Y$ we have

$$
d\left(p r_{1} f\left(x_{1}, y\right), p r_{1} f\left(x_{2}, y\right)\right) \leqq \lambda d\left(x_{1}, x_{2}\right) \text { for all } x_{1}, x_{2} \in X .
$$

It is clear that every contraction mapping in the first variable must be locally contraction in the first variable but the converse is not true in general. For example, let $X=Y=R, d(x, y)=|x-y|$ for all $x, y \in R$, and let $f: R \times R \rightarrow R \times R$ be defined by $f(x, y)=$ $\left(x y^{2} /\left(1+y^{2}\right), x y^{2} /\left(1+y^{2}\right)\right.$ ) (notice that both $X$ and $Y$ have the usual 
topology on the real line). For $y \in Y$ let

$$
r=|y|+1, \quad V(y)=(-r, r) \text { and } \lambda(y)=\frac{r^{2}}{1+r^{2}} .
$$

Then for any $x, x^{\prime} \in X$ and any $v \in V(y)$, we have

$$
\left|p r_{1} f(x, v)-p r_{1} f\left(x^{\prime}, v\right)\right|=\frac{v^{2}}{1+v^{2}}\left|x-x^{\prime}\right| \leqq \lambda(y)\left|x-x^{\prime}\right| .
$$

Hence $f$ is a locally contraction mapping in the first variable. Since

$$
\left|p r_{1} f(0, y)-p r_{1} f(1, y)\right|=\frac{y^{2}}{1+y^{2}} \text { and } \operatorname{Lim}_{y \rightarrow \infty} \frac{y^{2}}{1+y^{2}}=1,
$$

therefore the mapping $f$ is not contraction in the first variable.

Let us prove the first of our main results.

Proof of Theorem 1.1. Let $x_{0}$ be a fixed point in $X$. Define the mapping $g: Y \rightarrow Y$ as follows:

Let $y \in Y$. In order to define $g(y)$ we first define a sequence $\left\{t_{n}(y)\right\}$ as follows:

$$
t_{0}(y)=x_{0}, \quad t_{n}(y)=p r_{1} f\left(t_{n-1}(y), y\right), \quad n=1,2,3, \cdots .
$$

For simplicity we shall write $t_{n}$ to stand for $t_{n}(y)$.

We shall prove below, that as a consequence of local contractibility, it follows that $\left\{t_{n}\right\}$ is a Cauchy sequence in $X$ (see Lemma 1 below). But $(X, d)$ is complete so there is a point $t_{y}$ in $X$ such that $t_{n} \rightarrow t_{y}$.

Now define $g(y)=p r_{2} f\left(t_{y}, y\right)$. We are going to prove in Lemma 2 that $p r_{1} f\left(t_{y}, y\right)=t_{y}$.

We are also going to prove in Lemma 3 that $g$ is continuous.

Since $Y$ has the f.p.p., there is a point $y_{0} \in Y$ such that $g\left(y_{0}\right)=y_{0}$. By Lemma 2 we have $p r_{1} f\left(t_{y_{0}}, y_{0}\right)=t_{y_{0}}$. But $y_{0}=g\left(y_{0}\right)=$ $p r_{2} f\left(t_{y_{0}}, y_{0}\right)$. Henceforth $f\left(t_{y_{0}}, y_{0}\right)=\left(t_{y_{0}}, y_{0}\right)$ which completes the proof of the theorem.

Lemma 1. The sequence $\left\{t_{n}\right\}$ is a Cauchy sequence in $X$.

Proof. Since $f$ is a locally contraction mapping in the first variable, there exists a real number $\lambda \in[0,1)$ such that

$$
d\left(p r_{1} f\left(t_{n-1}, y\right), p r_{1} f\left(t_{n}, y\right)\right) \leqq \lambda d\left(t_{n-1}, t_{n}\right), \quad n \geqq 1 .
$$

By induction, we find

$$
d\left(t_{n}, t_{n+1}\right) \leqq \lambda^{n} d\left(t_{0}, t_{1}\right) .
$$


Using the triangle inequality, we find, for $m>n$,

$$
\begin{aligned}
d\left(t_{n}, t_{m}\right) & \leqq d\left(t_{n}, t_{n+1}\right)+\cdots+d\left(t_{m-1}, t_{m}\right) \\
& \leqq\left(\lambda^{n}+\lambda^{n+1}+\cdots+\lambda^{m-1}\right) d\left(t_{0}, t_{1}\right) \\
& =\lambda^{n} \frac{1-\lambda^{m-n}}{1-\lambda} d\left(t_{0}, t_{1}\right) \\
& <\frac{\lambda^{n}}{1-\lambda} d\left(t_{0}, t_{1}\right) .
\end{aligned}
$$

Since $\lambda^{n} \rightarrow 0$ as $n \rightarrow \infty$, this inequality shows that $\left\{t_{n}\right\}$ is a Cauchy sequence.

LEMMA 2. $p r_{1} f\left(t_{y}, y\right)=t_{y}$.

Let $u=p r_{1} f\left(t_{y}, y\right)$. By way of contradiction, suppose that $u \neq t_{y}$. Then $d\left(u, t_{y}\right)=\varepsilon>0$. Since $f$ is continuous, there exists an open set $U \times V$ in $X \times Y$ such that

$$
U \subset S_{\varepsilon / 4}\left(t_{y}\right),\left(t_{y}, y\right) \in U \times V \text { and } f(U \times V) \subset S_{\varepsilon / 4}(u) \times Y .
$$

Since $\lim _{n \rightarrow \infty} t_{n}=t_{y}$, there is a natural number $K \geqq 1$ such that $t_{n} \in U$ for all $n \geqq K$. But $p r_{1} f\left(t_{k}, y\right)=t_{k+1} \in U$. Therefore $f\left(t_{k}, y\right) \notin$ $S_{\varepsilon / 4}(u) \times Y$ which contradicts the fact that $f(U \times V) \subset S_{\varepsilon / 4}(u) \times Y$.

Therefore our assumption is incorrect and consequently we have the required conclusion.

LEMma 3. The function $g: Y \rightarrow Y$ defined as in the proof of Theorem 1.1 is a continuous function.

Proof. Let $y \in Y$ and $U$ be any open set containing $g(y)$. Then $f\left(t_{y}, y\right) \in X \times U$. Since $f$ is a continuous function at $\left(t_{y}, y\right)$, there is an open set $G$ in $Y$ and a positive real number $\varepsilon>0$ such that

$$
\left(t_{y}, y\right) \in S_{\varepsilon}\left(t_{y}\right) \times G \text { and } f\left(S_{\varepsilon}\left(t_{y}\right) \times G\right) \subset X \times U .
$$

Let $W$ be an open set in $Y$ and let $\lambda$ be a real number with $\lambda \in[0,1)$ such that $y \in W$ and

$$
d\left(p r_{1} f(x, v), p r_{1} f\left(x_{*}, v\right)\right) \leqq \lambda d\left(x, x_{*}\right) \text { for all } x, x_{*} \in X \text { and all } v \in W .
$$

Since $\lambda^{m} \rightarrow 0$ as $m \rightarrow \infty$, we can choose a natural number $n \geqq 1$ such that

$$
\lambda^{n}<\frac{\varepsilon}{8} \frac{1-\lambda}{d\left(t_{0}, t_{1}\right)+(\varepsilon \mid 8)}
$$




$$
d\left(t_{y}, t_{m}\right)<\frac{\varepsilon}{8} \quad \text { for all } \quad m \geqq n .
$$

Since $f\left(t_{n}, y\right) \in X \times U$ and $f$ is a continuous function at $\left(t_{n}, y\right)$, there exists a basic open set $U_{n} \times V_{n}$ in $X \times Y$ such that

$$
\begin{gathered}
\left(t_{n}, y\right) \in U_{n} \times V_{n}, \quad \begin{array}{l}
U_{n} \subset S_{\varepsilon / 8}\left(t_{y}\right), \quad V_{n} \subset G \cap W \\
f\left(U_{n} \times V_{n}\right) \subset X \times U .
\end{array}
\end{gathered}
$$

Since $f$ is continuous at $\left(t_{n-1}, y\right)$ and $f\left(t_{n-1}, y\right) \in U_{n} \times Y$, there exists a basic open set $U_{n-1} \times V_{n-1}$ in $X \times Y$ such that

$$
\begin{gathered}
\left(t_{n-1}, y\right) \in U_{n-1} \times V_{n-1}, \quad U_{n-1} \subset S_{\varepsilon / 8}\left(t_{n-1}\right), \quad V_{n-1} \subset V_{n} \quad \text { and } \\
\\
f\left(U_{n-1} \times V_{n-1}\right) \subset U_{n} \times Y .
\end{gathered}
$$

Inductively, suppose that $U_{n}, U_{n-1}, \cdots, U_{i}, V_{n}, V_{n-1}, \cdots, V_{i}(n-1 \geqq$ $i \geqq 1$ ) are chosen such that

$$
\begin{gathered}
\left(t_{i}, y\right) \in U_{i} \times V_{i}, \quad U_{i} \subset S_{\varepsilon / 8}\left(t_{i}\right), \quad V_{i} \subset V_{i+1} \quad \text { and } \\
f\left(U_{i} \times V_{i}\right) \subset U_{i+1} \times Y .
\end{gathered}
$$

Since $f$ is continuous at $\left(t_{i-1}, y\right)$ and $f\left(t_{i-1}, y\right) \in U_{i} \times Y$, there exists a basic open set $U_{i-1} \times V_{i-1}$ in $X \times Y$ such that

$$
\begin{gathered}
\left(t_{i-1}, y\right) \in U_{i-1} \times V_{i-1}, \quad U_{i-1} \subset S_{\varepsilon / 8}\left(t_{i-1}\right), \quad V_{i-1} \subset V_{i} \text { and } \\
f\left(U_{i-1} \times V_{i-1}\right) \subset U_{i} \times Y .
\end{gathered}
$$

In this way, the sets $U_{n}, U_{n-1}, \cdots, U_{0}, V_{n}, V_{n-1}, \cdots, V_{0}$ are defined with the above mentioned properties. We claim that $g\left(V_{0}\right) \subset U$.

To prove the claim, let $z \in V_{0}$. Then $\left(t_{0}^{\prime}, z\right) \in U_{0} \times V_{0}$, where $t_{0}^{\prime}=x_{0}$. Thus $f\left(t_{0}^{\prime}, z\right) \in U_{1} \times Y$, i.e., $t_{1}^{\prime}=p r_{1} f\left(t_{0}^{\prime}, z\right) \in U_{1}$. Consequently $d\left(t_{1}^{\prime}, t_{1}\right)<\varepsilon / 8$.

Using the triangle inequality we have $d\left(t_{0}^{\prime}, t_{1}^{\prime}\right)=d\left(t_{0}, t_{1}^{\prime}\right) \leqq d\left(t_{0}, t_{1}\right)+$ $d\left(t_{1}, t_{1}^{\prime}\right)<d\left(t_{0}, t_{1}\right)+\varepsilon / 8$. Since $f\left(U_{1} \times V_{1}\right) \subset U_{2} \times Y$ and $\left(t_{1}^{\prime}, z\right) \in U_{1} \times V_{1}$, therefore $f\left(t_{1}^{\prime}, z\right) \in U_{2} \times Y$, i.e., $t_{2}^{\prime}=p r_{1} f\left(t_{1}^{\prime}, z\right) \in U_{2}$ (For brevity we have used $t_{n}^{\prime}$ to stand for $\left.t_{n}(z)\right)$.

In the same way, we conclude that $t_{i}^{\prime}=p r_{1} f\left(t_{i-1}^{\prime}, z\right) \in U_{i}(i=1$, $2, \cdots, n)$.

Since $t_{n}^{\prime} \in U_{n}$ and $U_{n} \subset S_{\varepsilon / 8}\left(t_{y}\right)$, therefore $d\left(t_{n}^{\prime}, t_{y}\right)<\varepsilon / 8$. Using the triangle inequality we find, for $m \geqq n$,

$$
\begin{aligned}
d\left(t_{m}^{\prime}, t_{y}\right) & \leqq d\left(t_{y}, t_{n}^{\prime}\right)+d\left(t_{n}^{\prime}, t_{n+1}^{\prime}\right)+\cdots+d\left(t_{m-1}^{\prime}, t_{m}^{\prime}\right) \\
& \left.<\frac{\varepsilon}{8}+\lambda^{n} d\left(t_{0}^{\prime}, t_{1}^{\prime}\right)+\lambda^{n+1} \dot{a} \quad t_{1}^{\prime}\right)+\cdots+\lambda^{m-1} d\left(t_{0}^{\prime}, t_{1}^{\prime}\right)
\end{aligned}
$$




$$
\begin{aligned}
& =\frac{\varepsilon}{8}+\frac{\lambda^{n}}{1-\lambda}\left(1-\lambda^{m-n}\right) d\left(t_{0}^{\prime}, t_{1}^{\prime}\right) \\
& <\frac{\varepsilon}{8}+\frac{\lambda^{n}}{1-\lambda}\left(d\left(t_{0}, t_{1}\right)+\frac{\varepsilon}{8}\right)<\frac{\varepsilon}{8}+\frac{\varepsilon}{8}=\frac{\varepsilon}{4} .
\end{aligned}
$$

If $t_{z}=\lim _{n \rightarrow \infty} t_{n}^{\prime}$, then the above inequality shows that $d\left(t_{z}, t_{y}\right) \leqq \varepsilon / 4$. Therefore $\left(t_{z}, z\right) \in S_{\varepsilon}\left(t_{y}\right) \times G$ and consequently $f\left(t_{z}, z\right) \in X \times U$, i.e., $g(z)=p r_{2} f\left(t_{z}, z\right) \in U$.

Therefore our claim is proved and the proof of the lemma is completed.

The following result is an immediate corollary to Theorem 1.1.

Corollary 2.2. Let $(X, d)$ be a complete metric space, let $Y$ be a topological space with the f.p.p. and let $f$ be a continuous function from $X \times Y$ into $X \times Y$. If $f$ is a contraction mapping in the first variable, then $f$ has a fixed point.

A mapping $f: X \times Y \rightarrow X \times Y$ is called a strong contraction mapping in the first variable provided the following condition is satisfied: "There exists a positive constant $K$ such that for all $x_{1}, x_{2} \in X$ and all $y_{1}, y_{2} \in Y$, we have $d\left(p r_{1} f\left(x_{1}, y_{1}\right), p r_{1} f\left(x_{2}, y_{2}\right)\right) \leqq K d\left(x_{1}, x_{2}\right)$ whenever $x_{1} \neq x_{2}^{\prime \prime}$.

It is clear that there exists a contraction mapping in the first variable which is not strong contraction in the first variable. It is also clear that there exists a strong contraction mapping in the first variable which is not contraction mapping in the first variable. For examples, let $X=Y=R, d(x, y)=|x-y|$ for all $x, y \in R$ and let $f, g$ be two functions from $R \times R$ into $R \times R$ defined by the rules $f(x, y)=(2 x, y)$ and $g(x, y)=((x+y) / 2, y)$. Then it is clear that $f$ is a strong contraction mapping in the first variable with $k=2$ but not a contraction mapping in the first variable. It is also clear that $g$ is a contraction mapping in the first variable with $\lambda=1 / 2$ but not a strong contraction mapping in the first variable because

$$
\left|p r_{1} g(2, y)-p r_{1} g(0,0)\right|=\left|\frac{y}{2}+1\right| \text { and } \operatorname{Lim}_{y \rightarrow \infty}\left(\frac{y}{2}+1\right)=+\infty .
$$

As the following proof shows we have the following result.

Proposition 2.3. Let $(X, d)$ be a metric space which has no isolated point. If $f: X \times Y \rightarrow X \times Y$ is a continuous mapping and a strong contraction mapping in the first variable, then $\operatorname{pr}_{1} f(\{x\} \times Y)$ is a set consisting of a single element for all $x \in X$.

Proof. We shall prove the proposition by contradiction. Assume 
that there exist $x \in X$ and $y, y_{*} \in Y$ such that $p r_{1} f(x, y) \neq p r_{1} f\left(x, y_{*}\right)$. For simplicity, we shall write $t_{1}=p r_{1} f(x, y)$ and $t_{2}=p r_{1} f\left(x, y_{*}\right)$. Let $\varepsilon=d\left(t_{1}, t_{2}\right)$. Then $\varepsilon>0$. Let $S_{r}(p)$ denote the open sphere in $(X, d)$ with center at $p \in X$ and radius $r>0$.

Since $f$ is continuous, therefore there exist an open set $U$ in $X$ and open sets $V_{1}$ and $V_{2}$ in $Y$ such that

$$
(x, y) \in U \times V_{1}, \quad\left(x, y_{*}\right) \in U \times V_{2}, \quad U \subset S_{\varepsilon / 6 k}(x),
$$

$f\left(U \times V_{1}\right) \subset S_{\varepsilon / 6}\left(t_{1}\right) \times Y$ and $f\left(U \times V_{2}\right) \subset S_{\varepsilon / 6}\left(t_{2}\right) \times Y$.

Since $(X, d)$ has no isolated point, therefore there exists a point $u \in U-\{x\}$.

Therefore $d(u, x)<\varepsilon / 6 K$. But $f$ is a strong contraction mapping in the first variable, therefore we have

$$
d\left(p r_{1} f\left(u, y_{*}\right), p r_{1} f(x, y)\right) \leqq K d(u, x)<\frac{\varepsilon}{6} .
$$

Consequently $p r_{1} f\left(u, y_{*}\right) \in S_{\varepsilon / 6}\left(t_{1}\right)$ which is impossible because $p r_{1} f\left(u, y_{*}\right) \in S_{\varepsilon / 6}\left(t_{2}\right)$ and $S_{\varepsilon / 6}\left(t_{1}\right) \cap S_{\varepsilon / 6}\left(t_{2}\right)=\varnothing$.

Therefore we have the required contradiction and the proof of the proposition is completed.

3. Fixed point theorem and continuous height-selection. Let $f: X \times Y \rightarrow X \times Y$ be a continuous mapping. A point $y_{x} \in Y$ for which $p r_{2} f\left(x, y_{x}\right)=y_{x}$ is called a fixed $f$-height of $x$. The set

$$
\left\{y_{x}: y_{x} \text { is a fixed } f \text {-height of } x\right\}
$$

is called the fixed f-height of $x$ and is denoted by $F(f, x)$. The set

$$
\cup\{F(f, x): x \in X\}
$$

is called the fixed $f$-height of $X$ and is denoted by $F(f, X)$.

THEOREM 3.1. If $Y$ has the f.p.p., then $F(f, x) \neq \varnothing$ for all spaces $X$ and all $x \in X$. Conversely if $F(f, X) \neq \varnothing$ for some space $X$ and all continuous maps $f: X \times Y \rightarrow X \times Y$, then $Y$ has the f.p.p.

Proof. Let $Y$ have the f.p.p. and let $X$ be any topological space. Let $x \in X$ and $f: X \times Y \rightarrow X \times Y$ be any continuous map. Define the function $g: Y \rightarrow Y$ by the rule $g(y)=p r_{2} f(x, y)$. Then $g$ is continuous because $f$ is continuous. But $Y$ has the f.p.p., therefore there exists an element $y_{x} \in Y$ such that $g\left(y_{x}\right)=y_{x}$. Thus $p r_{2} f\left(x, y_{x}\right)=$ $y_{x}$, i.e., $F(f, x) \neq \varnothing$.

Conversely, suppose that $F(f, X) \neq \varnothing$ for some space $X$ and all continuous maps $f: X \times Y \rightarrow X \times Y$. Let $g: Y \rightarrow Y$ be any continuous 
map. Define $h: X \times Y \rightarrow X \times Y$ by the rule $h(x, y)=(x, g(y))$. Then $h$ is continuous. Since $F(h, X) \neq \varnothing$, there exists an element $a \in X$ such that $F(h, a) \neq \varnothing$. Let $y \in F(h, a)$.

Then $\operatorname{pr}_{2} h(a, y)=y$. It follows from the definition of $h$ that $g(y)=y$ which completes the proof of the theorem.

A continuous height-selection of $f$ is a continuous mapping $g: X \rightarrow F(f, X)$ such that $g(x) \in F(f, x) \quad(F(f, X)$ has the subspace topology from $Y$ ).

Let us state our next result in this section.

THEOREM 3.2. Let $X$ and $Y$ be topological spaces with the f.p.p., and let $f: X \times Y \rightarrow X \times Y$ be a continuous map. If $f$ has a continuous height-selection, then $f$ has a fixed point.

Proof. Since $Y$ has the f.p.p., by Theorem 3.1 the set $F(f, X) \neq \varnothing$. Let $g: X \rightarrow F(f, X)$ be a continuous height-selection of $f$. Define the map $h: X \rightarrow X$ by the rule $h(x)=p r_{1} f(x, g(x))$. We claim that $h$ is continuous. To prove our claim we let $x \in X$ and $G$ be any open set containing $h(x)$. Then $G \times Y$ is an open set containing the point $f(x, g(x))$. Since $f$ is continuous, therefore there exists an open set $U \times V$ containing $(x, g(x))$ such that $f(U \times V) \subset G \times Y$. But $g$ is continuous and $V$ is an open set containing $g(x)$. Therefore there exists an open set $W$ containing $x$ such that $g(W) \subset V$. Now, it is clear that $h(W) \subset G$. Hence $h$ is continuous.

Let $t \in X$ be a fixed point of $h$. Then $h(t)=t$, i.e., $p r_{1} f(t, g(t))=t$. Therefore $f(t, g(t))=(t, v)$ for some $v \in Y$. But $g(t) \in F(f, t)$. Therefore $p r_{2} f(t, g(t))=g(t)$, i.e., $f(t, g(t))=(u, g(t))$ for some $u \in X$. Henceforth $f(t, g(t))=(t, g(t))$ which completes the proof of the theorem.

THeOREM 3.3. Let $X$ and $Y$ be spaces with f.p.p. Let $f$ be a continuous function from $X \times Y$ into $X \times Y$. If $p r_{1} f(\{x\} \times Y)$ is a singleton set for any $x \in X$, then $f$ has a fixed point.

Proof. Choose a point $y_{0}$ in $Y$. By Theorem 3.1 there exists an element $x_{0} \in X$ such that $f\left(x_{0}, y_{0}\right)=\left(x_{0}, v\right)$ for some $v \in Y$. Apply Theorem 3.1 again, there exists an element $y_{x_{0}} \in Y$ such that $f\left(x_{0}, y_{x_{0}}\right)=\left(u, y_{x_{0}}\right)$ for some $u \in X$. But $p r_{1} f\left(\left\{x_{0}\right\} \times Y\right)$ is a singleton set, therefore $u=x_{0}$. Henceforth $f\left(x_{0}, y_{x_{0}}\right)=\left(x_{0}, y_{x_{0}}\right)$ which completes the proof of the theorem.

If we combine Theorem 3.3 and Proposition 2.3 then we can get the following result by observing that if $X$ has the f.p.p. then $X$ must be connected. 
CoRollary 3.4. Let $(X, d)$ be a metric space with the f.p.p., let $Y$ be a space with the f.p.p. and let $f$ be a continuous mapping from $X \times Y$ into $X \times Y$. If $f$ is a strong contraction mapping in the first variable, then $f$ has a fixed point.

Using the proof of Theorem 1.1 and the technique used in the proof of Theorem 3.2 one can obtain the following theorem.

THEOREM 3.5. Let $(X, d)$ be a complete metric space, let $Y$ be a topological space with the f.p.p. and let $f$ be a continuous function from $Y \times X$ into $Y \times X$. If $f$ is a locally contraction mapping in the second variable, then $f$ has a continuous height-selection and, hence, $f$ has a fixed point.

Actually the proof of Lemma $3(\S 2)$ gives us a way to construct such continuous height-selection. More explicitely if we define $h: Y \rightarrow F(f, Y)(F(f, Y)$ is a subspace of $X)$ by the rule $h(y)=t_{y}$, then $h$ will be a continuous height-selection of $f$.

The author wishes to express his appreciation to the referee for his valuable suggestions and remarks concerning the paper.

\section{REFERENCES}

1. G. Bredon, Some examples of fixed-point property, Pacific J. Math., 38 (1971), 571-573.

2. R. F. Brown, On some old problems of fixed-point theory, Rocky Mountain J. Math., 4 (1974), 3-14.

3. E. R. Fadell, Recent results in the fixed-point theory of continuous maps, Bull. Amer. Math. Soc., 76 (1970), 10-29.

4. S. Y. Husseini, The products of manifolds with the f.p.p. need not have the f.p.p., Amer. J. Math., 99 (1977), 919-931.

5. Sam B. Nedler, Jr., Sequences of constractions and fixed points, Pacific J. Math., 27 (1968), 579-585.

Received December 10, 1979 and in revised form April 6, 1981.

YARMOUK UNIVERSITY

IRBID, JORDAN 



\title{
PACIFIC JOURNAL OF MATHEMATICS
}

\section{EDITORS}

\author{
DONALD BABBITT (Managing Editor) \\ University of California \\ Los Angeles, CA 90024 \\ Hugo RossI \\ University of Utah \\ Salt Lake City, UT 84112 \\ C. C. MOORE and Arthur Agus \\ University of California \\ Berkeley, CA 94720
}

\section{J. DugundjI}

Department of Mathematics

University of Southern California

Los Angeles, CA 90007

R. FinN and J. Milgram

Stanford University

Stanford, CA 94305

\section{ASSOCIATE EDITORS}
R. ARENS
E. F. BeCKENBACH
B. H. NeumanN
F. WOLF
K. YoshidA

\section{SUPPORTING INSTITUTIONS}

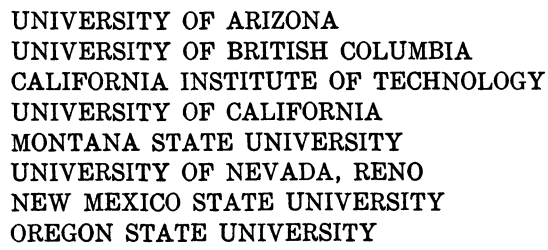

UNIVERSITY OF ARIZONA

UNIVERSITY OF BRITISH COLUMBIA

CALIFORNIA INSTITUTE OF TECHNOLOGY

UNIVERSITY OF CALIFORNIA

MONTANA STATE UNIVERSITY

UNIVERSITY OF NEVADA, RENO

NEW MEXICO STATE UNIVERSITY

OREGON STATE UNIVERSITY

\author{
UNIVERSITY OF OREGON \\ UNIVERSITY OF SOUTHERN CALIFORNIA \\ STANFORD UNIVERSITY \\ UNIVERSITY OF HAWAII \\ UNIVERSITY OF TOKYO \\ UNIVERSITY OF UTAH \\ WASHINGTON STATE UNIVERSITY \\ UNIVERSITY OF WASHINGTON
}

The Supporting Institutions listed above contribute to the cost of publication of this Journal, but they are not owners or publishers and have no responsibility for its content or policies.

Mathematical papers intended for publication in the Pacific Journal of Mathematics should be in typed form or offset-reproduced, (not dittoed), double spaced with large margins. Please do not use built up fractions in the text of the manuscript. However, you may use them in the displayed equations. Underline Greek letters in red, German in green, and script in blue. The first paragraph or two must be capable of being used separately as a synopsis of the entire paper. Please propose a heading for the odd numbered pages of less than 35 characters. Manuscripts, in triplicate, may be sent to any one of the editors. Please classify according to the scheme of Math. Reviews, Index to Vol. 39. Supply name and address of author to whom proofs should be sent. All other communications should be addressed to the managing editor, or Elaine Barth, University of California, Los Angeles, California, 90024.

50 reprints to each author are provided free for each article, only if page charges have been substantially paid. Additional copies may be obtained at cost in multiples of 50 .

The Pacific Journal of Mathematics is issued monthly as of January 1966. Regular subscription rate: $\$ 102.00$ a year (6 Vols., 12 issues). Special rate: $\$ 51.00$ a year to individual members of supporting institutions.

Subscriptions, orders for numbers issued in the last three calendar years, and changes of address shoud be sent to Pacific Journal of Mathematics, P.O. Box 969, Carmel Valley, CA 93924, U.S.A. Old back numbers obtainable from Kraus Periodicals Co., Route 100, Millwood, NY 10546.

\section{PUBLISHED BY PACIFIC JOURNAL OF MATHEMATICS, A NON-PROFIT CORPORATION}

Printed at Kokusai Bunken Insatsusha (International Academic Printing Co., Ltd.). 8-8, 3-chome, Takadanobaba, Shinjuku-ku, Tokyo 160, Japan. 


\section{Pacific Journal of Mathematics}

Vol. 99, No. $2 \quad$ June, 1982

Thomas E. Armstrong and Karel Libor Prikry, On the semimetric on a

Boolean algebra induced by a finitely additive probability measure . . . .249

Walter Russell Bloom, Strict local inclusion results between spaces of

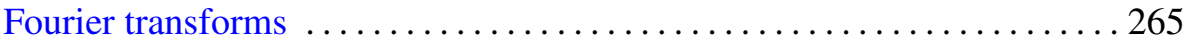

Richard Clark Brown, Notes on generalized boundary value problems in

Banach spaces. II. Infinite-dimensional extension theory ........... 271

Sui Sun Cheng, Isoperimetric eigenvalue problem of even order differential

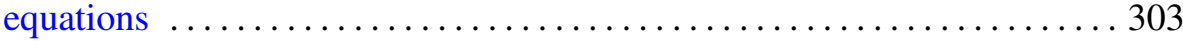

Lung O. Chung and Jiang Luh, Derivations of higher order and

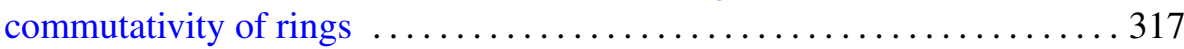

Ali Ahmad Fora, A fixed point theorem for product spaces . . . . . . . . . 327

Barry J. Gardner, Radical classes of regular rings with Artinian primitive

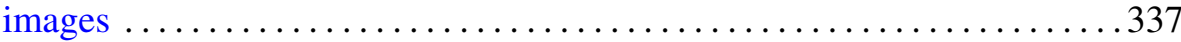

John Brady Garnett and Peter Wilcox Jones, BMO from dyadic BMO . . . 351

Allen E. Hatcher, On the boundary curves of incompressible surfaces . . . . 373

Richard Howard Hudson and Kenneth S. Williams, Resolution of

ambiguities in the evaluation of cubic and quartic Jacobsthal sums .....379

Viktor Losert, Counter-examples to some conjectures about doubly

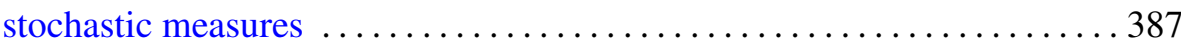

Kenneth Derwood Magill, Jr., P. R. Misra and Udai Bhan Tewari,

Structure spaces for sandwich semigroups

Mark Mandelker, Continuity of monotone functions

Kenneth Guy Miller, An index theorem and hypoellipticity on nilpotent Lie groups ......................................... 419

Evelyn M. Nelson, Homomorphisms of mono-unary algebras . . . . . . . . . 427

Marvin E. Ortel, The support of an extremal dilatation . . .

R. S. Pathak and O. P. Singh, Finite Hankel transforms of distributions . . . 439

Richard Cole Penney, The theory of ad-associative Lie algebras

Linda Ruth Sons, Zero distribution of functions with slow or moderate

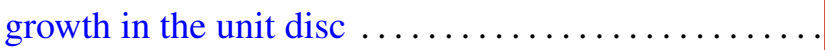

Russell Bruce Walker, Transversals to laminations 